\title{
Shoichi Asajima ed., Zaibatsu Kin'yu Kozo no Hikaku Kenkyu (Comparative Studies of Zaibatsu Financial Structures)
}

\author{
Reviewed by Juro Hashimoto \\ Hosei University
}

Japanese historians have devoted increasing attention to the economic groups known as the zaibatsu and during the past decade several books dealing with these groups have been published each year. Over time, both the focus of research and the methods of analysis scholars have used have changed. Zaibatsu Kin'yu Kozo no Hikaku Kenkyu ("Comparative Studies of Zaibatsu Financial Structures") is a case in point; and the best way to assess this work is to see how it accurately reflects this change.

Past studies of the zaibatsu have attempted to explain how they dominated Japan's prewar economy and to examine how this domination distorted the economy. After the introduction of business history as an academic discipline in Japan, scholars also began to investigate how the zaibatsu as economic organizations contributed to Japan's industrialization and whether in fact the various strategies adopted by the individual zaibatsu with regard to industrialization affected the ebb and flow of that process.

But these are not the concerns of the work in question; rather, the emphasis, as the title indicates, is on the zaibatsu's financial structures - their earning power, investment strategies, capital accumulation, and the like. The importance scholars attach to research on the zaibatsu prompted this work. The focus of the book is sharply defined: it considers the financial activities of the zaibatsu during the interwar period and does so with vivid historical detail.

The publication of a work of this nature has become possible because of the increased number of scholars studying the zaibatsu and because these scholars have developed among themselves a certain division of labor. This work is a collection of essays by Shoichi Asajima, Yutaka Kasuga, Masaru Udagawa, Takeshi Oshio and Tadashi Saito. The essays deal with the Mitsui, Mitsubishi and Sumitomo zaibatsu and with three of the "new" zaibatsu, i.e. Nissan, Nichitsu and Riken. Kasuga's career has been devoted to an investigation of the Mitsui zaibatsu; similarly, Udagawa has spent almost twenty years researching Nissan. Oshio and Saito have done likewise 
in their respective areas. The extensive research on the zaibatsu has, in general, been done by a large number of scholars, each of whom has devoted his attention to a particular group.

This book reflects the considerable work done by its authors, who offer their observations on the financial activities of the zaibatsu with which they are concerned. As the title suggests, the book also attempts a comparative approach to the organizations under consideration. The first object of comparison here is the zaibatsu's investment strategy; specifically, the authors have investigated whether the zaibatsu tended to stress corporate investment or corporate savings. Of particular interest in this regard is the question of how capital was raised when investments were made in excess of internal capital reserves. The authors have examined the operations of the central offices of the zaibatsu as well as the separate companies directly and indirectly tied to these organizations; they have also looked at the various companies that operated under the aegis of the zaibatsu.

The book is full of detail and cannot really be summarized here. Still, a few observations can be made with regard to common features among the zaibatsu. During the 1920s, Mitsui, Mitsubishi and Sumitomo handled almost all financing with internal capital reserves. But this was no longer possible in the 1930 s as their capital needs increased and from the late 1930s they were forced to borrow from the loan market. The new zaibatsu organized in the 1930s likewise depended on the loan market, although Nissan for one was very active in raising capital on the securities market. These changing patterns of capital financing reflect the way the Japanese economy itself evolved over time. The book's most notable contribution to our knowledge of the zaibatsu is its observation that the functions of the capital market were actually internalized by Mitsubishi, Sumitomo and Nichitsu. The concept of an internal capital market resembles that of the internal labor market. For Mitsui, the same capital market functions can be observed at the head office, Mitsui Bussan, and Mitsui Mining. The authors raise an extremely interesting and important point here. A cursory examination of the establishment of these internal capital markets would see them simply in terms of the relationships between the separate operations within a zaibatsu. But in fact, these markets may have developed as the primary financial activity of the particular zaibatsu; or, alternatively, there may be some inherent economic rationality in such markets which led to their establishment. In any case, here and elsewhere, the authors have given us a detailed treatment of the zaibatsu, one that, like the work that preceded this study, 
has deepened our understanding of the Japanese economy and Japanese management.

Translated by Stephen W. McCallion 